\title{
Justicia electoral en Oaxaca: entre los derechos de las mujeres y los derechos comunitarios*
}

\author{
LAURA R. VALLADARES DE LA CRUZ**
}

\begin{abstract}
Electoral Justice in OAXaca: Between Women Rights and COMMUNITARIAN Rights. The role of electoral authorities in conflict resolution in some municipalities of Oaxaca is analyzed. Authorities are appointed through indigenous normative systems. Attention is focused on two conflicts involving indigenous women candidates who were excluded from the ballot and unable to run for a position in the localgovernment. These women appealed to the corresponding electoral institutions and demanded their political-electoral rights to be respected. Some effects of the intervention of electoral authorities on indigenous autonomy are discussed, where indigenous men and women demand respect in order to solve their political dissent.
\end{abstract}

Key words: indigenous suffrage, women in elections and indigenous autonomy, electoral conflicts in Oaxaca, electoral authorities

\begin{abstract}
Resumen
Analizaré el papel que juegan las autoridades electorales en la resolución de conflictos en municipios oaxaqueños que nombran a sus autoridades mediante los sistemas normativos indígenas. Me centraré en dos conflictos que han involucrado a candidatas indígenas, quienes ante su exclusión para contender por un cargo en el ayuntamiento acudieron a las instancias electorales demandando que les fueran respetados sus derechos político-electorales. Discutiré algunos efectos que sobre las autonomías indígenas tiene la intervención de las autoridades electorales cuando las actoras y actores indígenas acuden a solicitar ésta para solucionar sus disensos politicos.
\end{abstract}

Palabras clave: sufragistas indígenas, mujeres elecciones y autonomía indígena, conflictos electorales Oaxaca, autoridades electorales

\section{Introducción}

$\mathrm{E}$ 1 estudio de los procesos y conflictos electorales en el estado de Oaxaca tiene ya una larga trayectoria, donde se ha dado cuenta de las disputas partidarias e interpartidistas, así como de los contextos de movilización sociopolítica que protagonizan diferentes actores políticos, sean movimientos, organizaciones indígenas, partidos y sus huestes, caciques y líderes y comunidades indígenas (Recondo, 2007). Existen también ricos trabajos que abordan las distintas formas de nombrar o elegir a las autoridades a través de los sistemas normativos indígenas (SNI) (Bailón Corres, Sorroza Polo y Eisenstadt, 2016). Sobre las disputas por acceder a cargos de representación, una de las vetas analíticas más sugerentes es la dedicada al estudio de la lucha de las mujeres indígenas por participar en las contiendas electorales y su accionar para ocupar diferentes cargos. En

\footnotetext{
* Artículo recibido el 05/04/17 y aceptado el 09/10/17.

** Departamento de Antropología de la Universidad Autónoma Metropolitana, Unidad Iztapalapa. Av. San Rafael Atlixco núm. 186, col. Vicentina, del. Iztapalapa, 09340, Ciudad de México. orCiD: http: //orcid.org/0000-0002-7577-6300
} 
este artículo pondré el énfasis analítico en el poder que tienen las autoridades electorales al emitir sus sentencias a favor de la inclusión de las mujeres en los procesos de nombramiento de sus autoridades, así como en las lógicas jurídicas que guían sus veredictos cuando resuelven dichas controversias. ${ }^{1}$ Es decir, haré una lectura sobre los derechos de las mujeres en el contexto de los derechos colectivos de los pueblos indígenas, a través de la revisión de las sentencias emitidas por las autoridades electorales relacionadas con dos conflictos que involucraron a mujeres indígenas. Es un abordaje desde la antropología del Estado que nos permitirá analizar las relaciones entre el Estado y su hegemonía y los pueblos indígenas como subalternos, que, según veremos, se trata de una batalla compleja en la cual los pueblos intentan defender su autonomía como tales, proceso que no es sencillo, ya que de forma paralela viven conflictos intraétnicos, sean políticos, generacionales o de género, y que tienen una de sus expresiones en las contiendas por la representación en sus municipios y agencias de policía o municipales.

Estas disputas tienen al Estado como un actor que en ocasiones funciona como aliado, en otras como juez y en otras más como un actor que desvanece o fortalece las autonomías, siempre y cuando no cuestionen su propia hegemonía jurídica y, por tanto, su poder. Vale la pena señalar que la intervención de las autoridades electorales siempre ocurre en respuesta a la solicitud que hacen los pueblos o ciudadanas y ciudadanos indígenas, y si bien en algunos casos la autonomía de los pueblos ha sido reconocida y fortalecida (Recondo, 2014), ${ }^{2}$ en otros, por ejemplo los relacionados con las disputas de las minorías excluidas de los procesos electorales -como las poblaciones de las agencias municipales, las mujeres y los avecindados-, se presentan tensiones entre los derechos comunitarios y los de las personas. En términos electorales, estos últimos aluden al principio de universalidad de voto, que es la piedra angular del derecho en esta materia. De manera que cuando las autorida- des electorales conocen e intervienen para resolver un conflicto en alguno de los 415 municipios de Oaxaca que nombran a sus autoridades por medio de los SNI, deben armonizar ambas fuentes de derecho.

Ahora bien, según los informes del Tribunal Estatal Electoral del Poder Judicial de Oaxaca (Santos López, 2015), los conflictos electorales se han ido incrementando año tras año. Los datos confirman que estamos ante un creciente proceso de judicialización de los conflictos político-electorales; en esto, las cifras hablan por sí mismas, pues los medios de impugnación en los que se solicitó la intervención del TEEPJO aumentaron en casi $600 \%$, pasando de 60 en 2006-2007 a 254 en 2009-2010, hasta llegar a 587 para 20122013.

Así, tan sólo entre 2012 y 2013 el tribunal electoral de Oaxaca dictó 1215 resoluciones, de las cuales 204 fueron turnadas a la Sala Superior del TEPJF. De éstas, únicamente 21 sentencias fueron revocadas, lo que nos habla de un alto nivel de eficacia. El teEPJo informó que de las 587 impugnaciones que recibió en ese periodo, sólo $17 \%$ (99 casos) procedió de municipios que eligen a sus autoridades por usos y costumbres. De este universo, en solamente 26 casos $(4.4 \%)$ se interpuso el recurso de juicio de protección de los derechos político-electorales. Hablamos entonces de una minoría de casos, atendiendo a la multiplicación de quejas que se reportan en la entidad (TEEPJo, 2013).

Podemos aventurar una explicación sobre este proceso de judicialización de los conflictos electorales en municipios y comunidades. Creo que acudir a las instancias locales y a la federal para resolver los conflictos, responde a la institucionalización y fiscalización de los procesos electorales en los pueblos indígenas por parte de las autoridades en la materia, pero también da cuenta de la voluntad de pueblos y comunidades por resolver por la vía pacífica -jurídica- los conflictos o disensos que se generan en el cambio de representantes y que son difíciles de procesar dentro de las propias comunidades, lo cual resulta encomiable frente a los tiempos violentos por los que atraviesa el país.

1 El órgano jurisdiccional del Poder Judicial de la Federación especializado para resolver las controversias electorales es el Tribunal Electoral del Poder Judicial de la Federación (TEPJF), con excepción de las acciones de inconstitucionalidad contra leyes electorales federales o locales que corresponden a la Suprema Corte de Justicia de la Nación (scJN). El TEPJF tiene como finalidad resolver las impugnaciones electorales y la protección de derechos políticos. Está regulado por el artículo 99 de la Constitución, la Ley Orgánica del Poder Judicial de la Federación y el Reglamento Interno del tePJF. Las salas regionales se integran por tres magistrados electorales y sus sedes son las ciudades designadas como cabecera de cada una de las cinco circunscripciones plurinominales en que se divide el país: Ciudad de México, Guadalajara, Monterrey, Toluca y Xalapa.

2 En otras entidades en donde no existe una legislación en materia electoral específica para pueblos indígenas, el TEPJF ha emitido sentencias paradigmáticas al resolver a favor de los pueblos o comunidades indígenas que han apelado a su derecho a elegir a sus autoridades de forma autónoma, es decir, sin la intervención de los partidos políticos, como los casos de Cherán en Michoacán (Aragón, 2013) o Ayutla de Libres en Guerrero (Méndez Lara, 2015; IEPC-EG, 2015). 
Vale la pena enfatizar que, si bien sólo $17 \%$ de los conflictos procede de los SNI, no se trata de un asunto recurrente pero sí enormemente significativo, debido a que las inconformidades expresadas en el texto de las sentencias que revisamos provienen de una minoría de hombres y mujeres indígenas excluida de las asambleas electorales de los municipios de Santo Domingo Nuxaá y San Bartolo Coyotepec. Ambos casos fueron llevados a todas las instancias electorales competentes, es decir, tuvieron que transitar por el Instituto Estatal Electoral y de Participación Ciudadana de Oaxaca (IEEPCO), el Tribunal Electoral del Estado de Oaxaca (TEEO), la Sala Regional del TEPJF con sede en la ciudad de Xalapa, Veracruz, y finalmente llegaron a la Sala Superior del TEPJF, con sede en la Ciudad de México. Cada instancia emitió una sentencia, pues mientras los implicados estén inconformes con el contenido del fallo, pueden apelar al nivel jurisdiccional subsiguiente. Como veremos, en estos dos conflictos, las autoridades electorales estatales y la sala regional avalaron los procesos electorales realizados en ambos municipios, respetando con ello sus lógicas y acuerdos comunitarios para elegir a sus autoridades, haciendo prevalecer el derecho indígena; sin embargo, cuando las disputas llegaron a la Sala Superior del TEPJF, las autoridades optaron por hacer prevalecer los derechos político-electorales de los ciudadanos frente a los derechos colectivos, lo que no sólo vulnera los derechos constitucionales indígenas, sino que abre la puerta a nuevos conflictos intracomunitarios.

Para dar cuenta de este proceso, en el primer apartado de este trabajo hablaré sobre las diferencias existentes entre la lucha de las mujeres indígenas por su inclusión política, que tiene una larga trayectoria y que se ha expresado tanto en el marco de las organizaciones indígenas mixtas como de mujeres, desde las cuales han negociado y exigido sus derechos, y cuya agencia política en múltiples ocasiones ha incidido positivamente para cambiar las tradiciones que las excluyen, con lo cual han pluralizado y democratizado las culturas políticas indígenas. En tanto, en el caso de las disputas individuales o de un reducido grupo de mujeres que impugnan las tradiciones que las excluyen, no se apela al derecho comunitario, sino a sus derechos políticos como personas. Esto pareciera sólo una diferencia de forma, sin embargo, tiene implicaciones de fondo, pues mientras que con las primeras experiencias se busca reformular para fortalecer los derechos comunitarios o colectivos, la segunda vía de disputa confronta desde una lógica jurídica no comunitaria la propia autonomía de los pueblos indígenas. En un segundo apartado haré un rápido recorrido por la institucionalidad electoral construida en materia indígena y los procesos de impugnación que pueden ser promovidos por los indígenas para demandar que sea respetada su forma de elegir o nombrar a sus autoridades. En el tercero analizaré las resoluciones del TEPJF relacionadas con dos municipios y que fueron promovidas por mujeres indígenas, donde me interesa mostrar que en los dos casos se procedió a realizar un control de convencionalidad y constitucionalidad en materia de derechos de las mujeres, que llevaron al tribunal a desconocer las asambleas comunitarias electorales, es decir, se apeló a normas no indígenas y se impuso el derecho de una minoría sobre una mayoría; por consecuencia, en estos casos, la lógica de la democracia, entendida como el gobierno de las mayorías, se invierte. En el

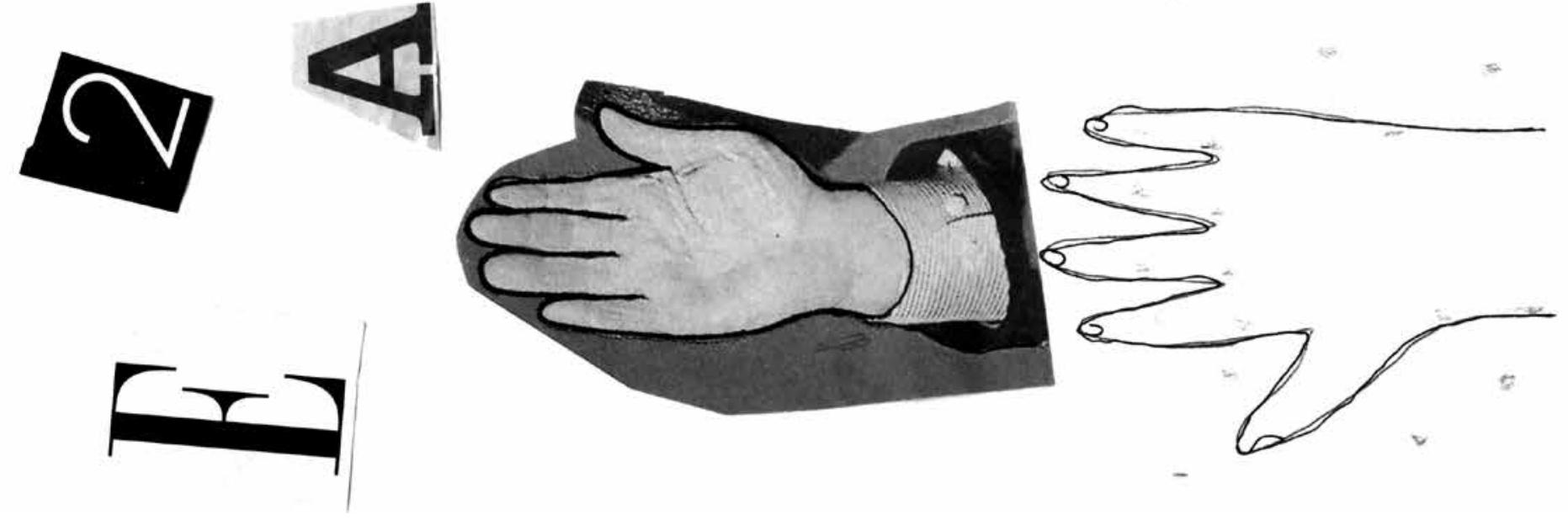


último apartado presentaré algunas reflexiones sobre los retos y tendencias de la justicia electoral para armonizar el derecho constitucional nacional con el derecho constitucional indígena.

\section{La lucha de las mujeres indígenas por la representación política}

Quisiera iniciar señalando que, pese a los avances en materia de representación política en los pueblos indígenas, cuando hablamos de la lucha de las sufragistas indígenas, una de las lamentables constantes es que ha estado caracterizada por una violencia de género. Especialistas en el tema han dado cuenta de los retos que han enfrentado las mujeres cuando se han atrevido a contender para ocupar un cargo de representación (Valladares de la Cruz, 2014; Dalton, 2012; Bonfil, Barrera y Aguirre, 2008; Velásquez, 2011 ; Vázquez García, 2011). Sobre Oaxaca en particular sobresalen los trabajos de Margarita Dalton y Cristina Velásquez. La primera ha efectuado investigaciones desde hace por lo menos dos décadas en las que ha analizado los sinuosos caminos seguidos por las mujeres desde que deciden contender por un cargo, en los procesos de campaña, y durante las gestiones de aquellas quienes han logrado ser presidentas municipales, mostrando que, independientemente de la vía por la que lleguen al cargo, sea por algún partido político o por medio de asambleas comunitarias, en general se ha ejercido una violencia de género contra ellas en todas sus dimensiones: emocional, económica, simbólica y física, pues pronto encuentran que su participación está condicionada por su género. Hay prácticas sociales e ideas comunes sobre lo que una mujer debe y no debe hacer. Existen raigambres culturales, morales y religiosas que especifican la posición social de la mujer y en éstas no se incluye la de practicar la política pública, ocupar un puesto de gobierno o ser autoridad (Dalton, 2012: 169).

A pesar de estas condiciones, las indígenas han luchado vigorosamente por su derecho a participar en los asuntos políticos en todos los niveles de la vida política de sus pueblos y en el nacional, donde han logrado conquistar espacios dentro de diversas organizaciones, instituciones, así como en diferentes niveles de poder de la Federación. En este sendero, han creado sus propias organizaciones, como la Coordinadora Nacional de Mujeres Indígenas (Conami), y también participan activamente en organizaciones supranacionales, como el Fondo Internacional de Mujeres Indígenas (FIMI), el Enlace Continental de Mujeres Indígenas o la Alianza de Mujeres Indígenas de México y Centroamérica, entre otras (Valladares de la Cruz, 2008). Retomo aquí una parte de la agenda que la Conami dio a conocer en 2012 reivindicando su compromiso con sus pueblos y sus derechos como mujeres:

Reconocemos que en nuestras comunidades es necesario seguir fortaleciendo el diálogo con nuestras autoridades comunitarias, en el interior de organizaciones y en la comunidad misma, para continuar caminando, a fin de que hombres y mujeres indígenas caminemos juntos en la toma de decisiones sobre la vida comunitaria [Conami, 2012: 39].

Asimismo, en lo referente a su posicionamiento sobre el papel que están teniendo las autoridades electorales, señalaron:

Instamos al IFE y al TEPJ a reconocer los sistemas normativos propios de nuestras comunidades y pueblos, a buscar mecanismos que coadyuven a la resolución de conflictos entre ambos sistemas. Demandamos al Estado mexicano voluntad política para establecer una relación cordial, de respeto, reconocimiento y valoración hacia las mujeres y pueblos indígenas [Conami, 2012: 40-41].

Como parte de esta constante lucha, en agosto de 2015 un grupo de 80 líderes de diversos pueblos indígenas del país constituyó la Asamblea Nacional Política de Mujeres Indígenas (ANPMI) para luchar por sus derechos políticos y enfrentar con sus pueblos los grandes problemas que los afectan, como la instauración de megaproyectos en sus territorios, la pobreza, la discriminación, el racismo, la violencia de género, los feminicidios, entre los más relevantes. Durante su segundo congreso, realizado en octubre de 2016 en la ciudad de Oaxaca, dejaron asentado en su declaración final su posicionamiento sobre la entidad anfitriona en los siguientes términos:

8. En el caso del estado de Oaxaca, el Consejo General del Instituto Estatal Electoral y de Participación Ciudadana del estado de Oaxaca (IEEPCO), ha emitido el acuerdo IEEEPCO-CG-SNI-4/2015, mismo que en su considerando 13, previene a los 417 municipios que se rigen por Sistema Normativos Internos, para que apliquen, respeten y vigilen la perspectiva de género, así como el principio de universalidad del voto en la renovación de sus próximas autoridades municipales y que de no incorporar dichos principios no podrá ser calificada como válida la correspondiente elección de concejales al ayuntamiento. Al respecto manifestamos. Es cierto que la autonomía, autodeterminación y vida colectiva no significa excluir la 
participación de las mujeres, y es impostergable el derecho que tenemos las mujeres indígenas de votar y ser votadas, sin embargo, instamos a las autoridades electorales del Estado de Oaxaca para que informen y consulten a las mujeres indígenas sobre las determinaciones anteriormente referidas y los mecanismos que el IEEPCO está implementando en el tema, para garantizar que no se vulnere a las mujeres ni las coloque en riesgo de violencia política. Exigimos que las Autoridades, Defensoría y Tribunales Electorales escuchen a las mujeres indígenas y valoren con perspectiva intercultural y de género en los casos en los que ellas sean afectadas, así como a dar seguimiento y acompañamiento puntual y cercano a las mujeres indígenas que sean incorporadas a los gobiernos municipales [ANPMI, 2016].

Es decir, para la APMI, una de las preocupaciones de las mujeres es cómo lograr incidir en el campo público sin constituirse como un sector que atente contra los designios comunitarios, pero expresa una decisión de cambiar la exclusión y, por tanto, la subrepresentación política que ha sido una constante a lo largo de la historia. La tradición les da la razón, pues, de acuerdo con las pesquisas de Dalton (2012: 153), sólo 25 mujeres habían sido presidentas municipales desde que se aprobó la Constitución de 1917 (la de Oaxaca data de 1921) y hasta finales del siglo xx. Siguiendo sus trayectorias, encontró que estas mujeres tienen historias de liderazgo excepcional y se han distinguido dentro de sus comunidades, partidos, iglesias y escuelas por su compromiso social. En muchos casos, provienen de una familia donde algún pariente cercano ha tenido un cargo de representación política; es decir, hay una genealogía de participación política o de lucha por la tierra y los derechos comunales o humanos. En otras situaciones, su elección o participación se debió a que su familia ha tenido importantes intereses económicos en el municipio. Dalton afirma que, dadas las costumbres y tradiciones acerca de la participación de la mujer en la vida política, este liderazgo o situación familiar no las hubiera conducido por sí sólo a ser presidentas municipales. Si lo pudieron hacer fue por otras circunstancias políticas mundiales y nacionales o glocales, como el feminismo y las luchas de los movimientos amplios de mujeres, así como el reconocimiento de los derechos humanos de las mujeres por parte de las Naciones Unidas.

A estas trayectorias podemos sumar la construcción de un movimiento organizado de mujeres en Oaxaca, expresado en la Asamblea de Mujeres Indígenas de Oaxaca (АMIO), constituida en 2010 en el marco de los graves conflictos sociales que vivió la entidad durante el sexenio del exgobernador Ulises Ruiz Ortiz (2004-
2010). Se conformaron como asamblea aludiendo a la forma tradicional de organización de sus pueblos indígenas, con una clara perspectiva interseccional: étnica, de género y clase. La asamblea está integrada por líderes, mujeres que fueron o son autoridades, profesionistas, abogadas y defensoras de los derechos humanos. Proponen una agenda dirigida a incidir, desde una perspectiva feminista y de interculturalidad, en la resolución de los problemas políticos de la entidad y sus comunidades. Es un movimiento muy significativo que a partir de un fortalecimiento de su etnicidad lucha desde diferentes trincheras para derribar la cultura patriarcal y la violencia estructural que las excluye, siempre reivindicando su pertenencia étnica y de género (Martínez Cruz, 2016). Me parece que ésta es una de las expresiones más nítidas de la agencia política de las mujeres indígenas de Oaxaca $\mathrm{y}$, sin duda, tiene un papel fundamental para abrir espacios de reflexión y de acceso a la toma de decisiones y a la creación de una política pública donde la perspectiva de género sea transversal, con lo cual abonan el camino para la configuración de escenarios de mayor equidad de género tanto en sus pueblos como en las instancias de gobierno.

\section{El poder de decisión de las autoridades electorales}

Ahora bien, en lo que se refiere al andamiaje electoral y la incorporación de los derechos político-electorales de los pueblos y comunidades indígenas en la entidad, tenemos la exhaustiva revisión de las leyes y códigos electorales del estado realizada por David Recondo en 2007, en la que muestra cómo el Estado mexicano y el gobierno oaxaqueño han "cambiado todo para que todo siga igual”, lo que el autor denomina la política del gatopardo, es decir, que en las últimas cuatro décadas se han realizado cambios sustantivos en las leyes y códigos electorales cuyo objetivo velado ha sido mantener el poder del estado en manos de un priísmo cuya legitimidad se ha ido minando como resultado de sus gestiones clientelares y su incapacidad para resolver los conflictos políticos que se multiplican tanto como las confrontaciones partidistas e intrapartidistas. En Oaxaca, como en otras entidades, existe un escenario de confrontación electoral cada vez más plural, alentada por la incapacidad de los gobiernos para atender las demandas de organizaciones y movimientos sociales, que reclaman su inhabilidad y desinterés por reducir la desigualdad y la exclusión social, así como su fracaso para detener la violencia estructural que ha dibujado la historia reciente de esta compleja y diversa entidad. 
De tal forma, la conflictividad electoral en el estado tiene ya una larga data.

Sin embargo, me parece que aun con los avances de lo que podríamos llamar un nuevo pluralismo jurídico, las últimas modificaciones reglamentarias tienden a colocar a las autoridades electorales por encima de los propios pueblos indígenas y están incidiendo en la configuración de una nueva geometría política en la entidad. Siguiendo a Recondo, ciertamente continúa cambiando todo, en cuanto a normas y lo relacionado a mantener o recuperar la hegemonía unipartidista, pero para los pueblos indígenas parece que ya nada será igual, pues se está poniendo en entredicho uno de los pilares de su autonomía: el derecho a decidir la forma en que eligen o designan a sus autoridades.

De acuerdo con el análisis de las sentencias emitidas por el TEPJF entre 1999 y 2012 efectuado también por Recondo (2014: 2) en relación con las elecciones por los SNI, se encontró que en el esfuerzo por armonizar los derechos político-electorales del ciudadano y los derechos de la comunidad existen vaivenes, ya que las primeras disputas conocidas por las autoridades electorales, entre 1999 y 2012, se resolvieron atendiendo al derecho comunitario, es decir, avalando las dinámicas y formas de elección de las asambleas comunitarias. Empero, se identificó que, en las siguientes resoluciones -a pesar de que en sus argumentaciones se alude a un discurso de la ciudadanía pluricultural $\mathrm{y}$, por ende, a los derechos de los pueblos indígenasse protegen los derechos individuales.

Ahora bien, decíamos que la mayoría de las controversias están relacionadas con desacuerdos en tres grandes campos: el primero conformado por aquellos ciudadanos que residen en las localidades aledañas (agencias de policía o municipales), que exigen su derecho a participar para elegir o ser electos en los cargos de consejales en sus ayuntamientos. Esto obedece a que tradicionalmente en la cabecera municipal se elige a las autoridades municipales y las agencias eligen a sus autoridades sin intervención de la población de la cabecera municipal. El segundo es el vinculado con las disputas de las mujeres por ejercer su derecho ciudadano a participar en las asambleas comunitarias para ejercer su derecho a votar y ser votadas. El tercero tiene que ver con los "avecindados", es decir, con los nuevos residentes de las comunidades y municipios, que en general se les excluye por varios motivos, por ejemplo, por su calidad de fuereños o porque su derecho está ligado con el cumplimiento de sus obligaciones comunitarias (Recondo, 2014).

Si bien la legislación electoral habla de reconocer las particularidades con que se nombra a las autoridades, en la Guía de actuación para funcionarios y funcionarias electorales en materia de género en elecciones por sistemas normativos internos (Observatorio Electoral de Género-IEEPCO, 2016: 8) se hace prevalecer el principio de universalidad del voto; veamos como expresión de ello lo que señalan los lineamientos éticos para los funcionarios electorales: 1) proporcionar información completa, 2) promover el intercambio de ideas, 3) ge nerar empatía y comprensión sobre las implicaciones que tiene para la costumbre y para los procedimientos electorales de las comunidades realizar cambios normativos, 4) enfatizar que toda norma debe cumplirse, y que si hay una inconformidad, existen los recursos jurídicos para presentarla, y 5) ofrecer una visión de oportunidad y una perspectiva positiva respecto a la incorporación de las mujeres a cargos de autoridad.

La guía explica claramente las lógicas y la diversidad de formas a través de las cuales participan las mujeres indígenas en la toma de decisiones de sus pueblos. Se habla, por ejemplo, de la existencia de una ciudadanía familiar, que, de acuerdo con Velásquez (2006), es una ciudadanía amplia que se ejerce en el marco de las unidades familiares, ya que es común que en algunos municipios con mucha migración masculina las mujeres asuman la responsabilidad del cargo y cumplan el servicio en representación del hombre. Aunque constituye una forma de sustitución, en la práctica, esta participación ha tenido efectos importantes y positivos que permiten a la sociedad valorar la capacidad de las mujeres para gobernar. También se menciona que hay comunidades en donde se toma como válido para el jefe de hogar el que alguna de sus hijas con preparación académica asuma cargos en el ayuntamiento (Observatorio Electoral de Género-IEePco, 2016: 16; Velásquez, 2011). El documento es interesante, bien sustentado, pero no obstante que se argumenta que se debe reconocer la diversidad de prácticas y costumbres culturales y políticas para entender sus lógicas, la norma es la norma y debe cumplirse, y no se refiere a las normas comunitarias o indígenas sino a las del juego electoral. Es decir, prevalecen las normas constitucionales y las emanadas de convenciones internacionales, en materia de género, sobre las consuetudinarias.

Sin duda, los impactos de las normas electorales en materia de equidad y paridad de género han provocado cambios relevantes en el corto plazo; por ejemplo, en el proceso electoral de 2013, las cifras aportadas por las autoridades electorales estatales indican que sólo 16 mujeres ocuparon la presidencia municipal de un total de 570 municipios. De este grupo, ocho fueron electas en municipios de sistemas normativos internos (Observatorio Electoral de Género-IEEPCO, 
2016: 19-20). En contraste con el proceso electoral de 2016, atendiendo a las reformas en materia de paridad de género, aprobadas en enero de 2014, para candidaturas de legisladores federales y locales, así como atendiendo a la última reforma del artículo segundo constitucional. ${ }^{3}$ En este nuevo escenario, el número de mujeres electas ascendió de manera importante, en un orden de cinco veces frente al proceso de 2013 (IEEPCO, 2016). De acuerdo con los datos proporcionados por la consejera electoral del IEEPCO, Rita Bell López, 1100 mujeres ocupan cargos en municipios regidos por sistemas normativos, de los cuales 21 eligieron a mujeres como presidentas municipales, lo que constituye $5 \%$ de los municipios que eligen por usos y costumbres. Si bien es una cifra muy reducida, en el contexto de los municipios indígenas representa un giro significativo.

Sobre este particular, el TEPJF ha establecido claramente que las prácticas respecto del ejercicio del voto en los pueblos y comunidades indígenas deberán estar sujetas al principio de universalidad del voto, criterio sustentado en la tesis CLI / 2002, la cual resolvió que:

Si en una comunidad indígena no se permitiera votar a los ciudadanos que tienen derecho por determinadas prácticas tradicionales, entonces dicha restricción se traduciría en la negación o anulación de su derecho fundamental a sufragar, y ello significaría la transgresión al principio de igualdad, visto desde el punto de vista subjetivo que emana de dicha norma, el derecho a no ser discriminado injustamente; por lo tanto, esta situación violatoria de derechos fundamentales, queda excluida del ámbito de reconocimiento y tutela de los derechos de los pueblos y comunidades indígenas previstos por la Constitución federal, al resultar incompatible con los derechos fundamentales que han quedado precisados; por lo que, en consecuencia, esa práctica o tradición de una comunidad indígena no tendría el carácter de democrática [Jiménez Bartlett y Aguilar Contreras, 2013: 44].

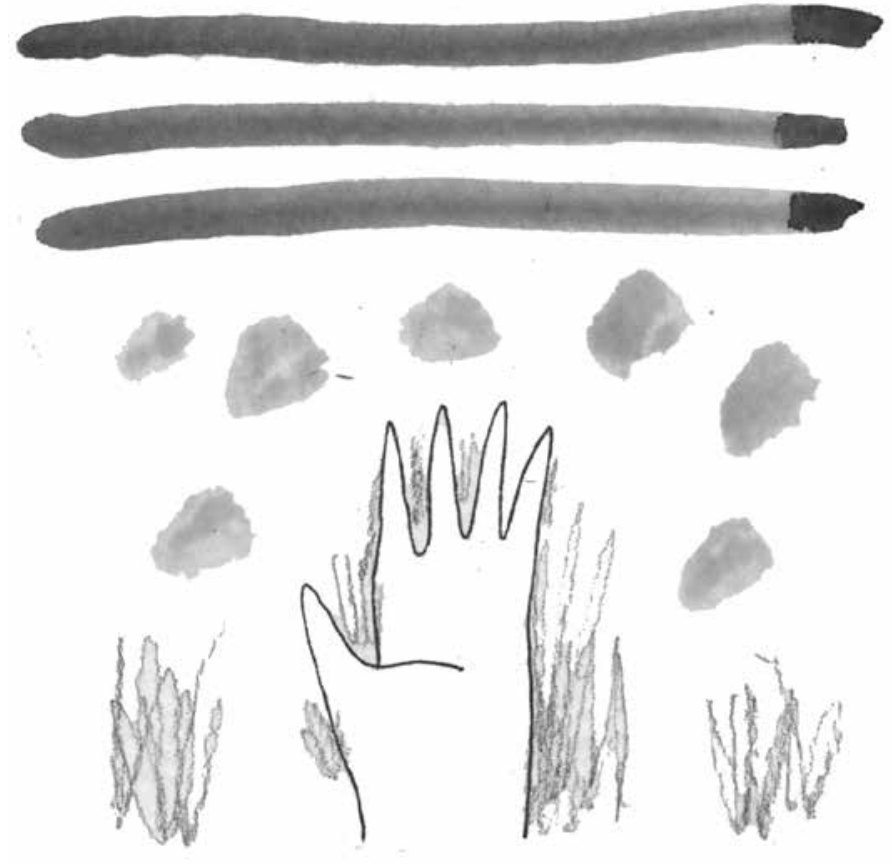

Es aquí donde se presentan las mayores tensiones entre los sistemas jurídicos indígenas y el derecho electoral nacional, como veremos en los conflictos generados en dos municipios.

\section{Dos sentencias del TEPJF y su impacto en la vida de los pueblos indígenas}

\section{Santo Domingo Nuxaá, Nochixtlán, Oaxaca}

La primera sentencia que comentaré es la relativa al conflicto electoral surgido en el municipio de Santo Domingo Nuxaá ("Pueblo Nuevo", en mixteco), perteneciente al distrito de Nochixtlán. ${ }^{4}$ La controversia empezó cuando Juan Sánchez y otros vecinos del

3 Posteriormente la tesis emitida por la scun que señala en la tesis Jurisprudencia 672015: la Paridad de Género debe observarse en la postulación de candidaturas para la integración de órganos de representación popular federal, estatales y municipales (aprobada el 6 de mayo de 2015). Unos meses después, en enero de 2016, las autoridades electorales hicieron llegar a los municipios de Oaxaca que se rigen por SNI un comunicado con el siguiente texto: "Le informo que la Constitución General de la República así como la Constitución Local, establecen que los pueblos y comunidades indígenas, deben garantizar en la elección de sus autoridades el derecho de las mujeres de votar y ser votadas en condiciones de igualdad, por lo cual su asamblea general comunitaria deberá convocar a todas las mujeres de su municipio para que ejerzan su derecho, generando las condiciones suficientes y necesarias para que las mujeres participen en condiciones de igualdad en la elección e integración de su ayuntamiento" (Observatorio Electoral de Género-IEEPCO, 2016: 8). Aquí se refieren a la modificación a la fracción III del apartado A del art. $2^{\circ}$ constitucional publicada en el Diario Oficial de la Federación el 22 de mayo de 2015 <http://info4.juridicas.unam.mx/ijure/fed/9/3.htm?s=> [10 de diciembre de 2015].

4 SUP-REC 438/2014 juicio promovido por las ciudadanas Inés Martínez López y Zilpa Castellanos López en contra de los acuerdos de la Asamblea Electoral del municipio de Santo Domingo Nuxaá, Oaxaca, en virtud de que existieron varias anomalías de procedimiento, entre ellas la exclusión de las mujeres negándoles el derecho de votar y ser votadas. 
municipio acudieron al IEEPCO a interponer un juicio de protección de sus derechos político-electorales, en virtud de que en la asamblea comunitaria de su municipio los habían excluido de su derecho de votar y ser votados y dejaron asentado que lo mismo ocurrió con las mujeres. Así se iniciaría un largo recorrido entre las diferentes instancias que pueden conocer y resolver sobre un conflicto electoral. Si bien una de las características de los conflictos en esta materia es que son resueltos en un tiempo muy corto, pueden alargarse si los quejosos no están de acuerdo con la resolución de alguna de las instancias electorales y pueden acudir a otra de mayor jerarquía. Esto puede hacer que un conflicto se prolongue por varios meses, lo cual en términos de mandato de gobierno es desproporcionado si consideramos que una gestión municipal dura tres años y en muchos municipios indígenas el cargo es de solamente un año.

El conflicto jurídico electoral de Santo Domingo Nuxaá comenzó con una reunión con la Coordinadora de la Dirección Ejecutiva de Sistemas Normativos Internos del IEEPCO, luego transitó del Tribunal Estatal Electoral a la Sala Regional del Tribunal Electoral con sede en Xalapa, Veracruz, para concluir en el Tribunal Superior del tePJF, quien declaró la nulidad de las dos asambleas electorales realizadas en el municipio debido a que excluyeron a las mujeres de la comunidad, no obstante dichas asambleas habían sido previamente validadas por el IEEPCO y después por la Sala Regional.

Para llegar a la nulidad de las asambleas comunitarias se debió transitar por un largo camino de ocho meses, que terminó cuando la Sala Superior del TEPJF, al analizar el expediente y efectuar un control de constitucionalidad, relativo al cumplimiento del artículo $2^{\circ}$ constitucional, concerniente a los límites de la autonomía de los pueblos indígenas y de convencionalidad, relativo el cumplimiento de los derechos fundamentales de las mujeres en distintas convenciones internacionales, concluyó que sí se violentaron los derechos de las mujeres, toda vez que, a pesar de haber asistido 71 mujeres a la última asamblea comunitaria, se percibía que su presencia significó la adhesión de las mujeres al acuerdo tomado en las asambleas anteriores en donde fueron excluidas, por lo que se consideraba que se les obligó a pronunciarse por una decisión tomada previamente, lo que daba cuenta de que no se les otorgó voz y, por tanto, el procedimiento se encontraba viciado. Así, después de ocho meses, la Sala Superior revocó los acuerdos de validez a las asambleas electorales otorgados por el Tribunal Estatal Electoral y por la Sala Regional. La sentencia fue notificada a la LXII Legislatura del Congreso de Oaxa- ca, con el mandato de que se convocara a una asamblea extraordinaria.

Fue un proceso muy prolongado sin que concluyera el conflicto, porque aún estaba por convocarse a la asamblea extraordinaria mandatada por la Sala Superior del TEPJF (al menos hasta ese momento llega el expediente). Si consideramos que se trata de una gestión municipal de tres años, casi una tercera parte del periodo ha estado dedicado a resolver el conflicto, lo cual significa un desgaste y tensiones para la población y autoridades del municipio. Me parece pertinente comentar el hecho de que fueron dos mujeres las que impugnaron un procedimiento tradicional, que si bien las excluía, hubo voluntad de reponerlo incorporando a un número importante de mujeres -71 de 462 asistentes-, y a pesar de ello la Sala Superior cuestionó su capacidad de decisión, al argumentar que sólo avalaron el nombramiento de autoridades de las asambleas comunitarias previas porque seguramente iban con ese mandato, sin embargo, me parece que su participación no podría verse de inmediato como coacción, ya que cabría la posibilidad de que las mujeres no tuvieran inconveniente en refrendar una decisión considerada adecuada para la colectividad.

Creo que un procedimiento como éste tiene efectos en dos sentidos: por un lado, vulnera las decisiones autónomas de una asamblea comunitaria, pues, como nunca antes, es ahora una instancia externa a la comunidad quien califica de válidas o erráticas sus decisiones y esto desestabiliza a la instancia fundamental de toma de decisiones de este pueblo, es decir, a la propia asamblea comunitaria. Sobre este impacto da cuenta el expediente, puesto que se incorporaron algunos comentarios de los habitantes de una de las agencias del municipio, quienes expresaron que "no se enteraron de la nulidad del proceso electoral" y que no asistirían a una nueva asamblea, pues ya lo habían hecho en dos ocasiones previas. Por otro lado, es muy probable que en las siguientes asambleas comunitarias se convoque a las mujeres del municipio; esperemos que este proceso contribuya a fortalecer escenarios de inclusión y no tenga como consecuencia crear nuevas tensiones y faccionalismos que lleven a desestabilizar la organización comunitaria a mediano o largo plazo.

\section{San Bartolo Coyotepec}

El segundo caso que me interesa tratar es el conflicto que se manifestó en la interposición de un juicio promovido por la ciudadana Abigail Vasconcelos 
Castellanos, quien demandaba la protección de sus derechos político-electorales en virtud de que en la elección de representantes del ayuntamiento de San Bartolo Coyotepec, Oaxaca, se excluyó a las mujeres. ${ }^{5}$

Esta sentencia alude al conflicto ocurrido después de la asamblea comunitaria electoral del 20 de octubre de 2013, cuando Abigail Vasconcelos Castellanos acudió a la Dirección Ejecutiva de Sistemas Normativos Internos del IEEPCO a manifestar que las mujeres fueron discriminadas, pues se les impidió ser consideradas como candidatas para integrar el ayuntamiento. Aunque la implicada señaló que, si bien ella no tenía intención de ser candidata, sí reclamaba el derecho de las mujeres a participar activamente en el proceso de elección.

Como parte del procedimiento, la Dirección Ejecutiva convocó a las autoridades del ayuntamiento a una reunión de trabajo en la que se acordó la realización de una asamblea extraordinaria para reponer el procedimiento electoral. Sin embargo, las autoridades de San Bartolo decidieron que se repondría solamente el procedimiento a partir de la designación del cargo de tercer regidor, es decir, manteniendo a las autoridades designadas como presidente municipal y síndico. La asamblea dispuso que en esta ocasión la postulación sería a través de la formulación de ternas de candidatos integradas tanto por hombres como por mujeres. En dicha asamblea se eligieron nuevamente sólo hombres para ocupar los cargos, procedimiento que fue calificado y validado por el Consejo General del IEEPCO, pues contó con la participación de las mujeres del municipio. Por ello, Abigail Vasconcelos interpuso un primer juicio de protección de sus derechos políticoelectorales, con el fin de controvertir el acuerdo de la asamblea. Empero, al revisar el procedimiento, la Sala Regional Xalapa del TEPJF avaló la resolución emitida por el teEpJo. Así, en enero de 2014, Abigail Vasconcelos interpuso un segundo juicio de protección de sus derechos electorales, y de nuevo la Sala Regional de Xalapa confirmó la resolución de validez de la asamblea extraordinaria emitida por el TEEPJO.

Ante este hecho, la inconforme interpuso un recurso de reconsideración, que llevó a que el caso fuera recibido por la Sala Superior del TEPJF, quien después de estudiarlo consideró que el agravio expresado por Abigail Vasconcelos era fundado, porque hubo una indebida interpretación del principio constitucional de igualdad jurídica entre el hombre y la mujer y, por tanto, la sentencia impugnada vulneró el derecho de voto pasivo de la recurrente, consistente en la imposibilidad de acceder a un cargo de elección popular en condiciones de igualdad. Por tal motivo declaró la nulidad de la elección de los integrantes del municipio deSan Bartolo Coyotepec. Entonces, deberían efectuar otra asamblea extraordinaria para garantizar el voto de hombres y mujeres en condiciones de igualdad, además de informar a la comunidad los derechos de las mujeres a votar y ser votadas.

Este procesoduró seis meses, eintervinieron todas las autoridades y niveles de jurisdicción electoral: estatal (Dirección Ejecutiva de Sistemas Normativos Internos y Consejo General del IEEPCO), regional (Sala RegionalXalapa) y federal (Sala Superior del TEPJF), donde las tres primeras avalaron el procedimiento electoral de San Bartolo, mientras que la autoridad federal lo revocó después de llevar a cabo un estudio de control de constitucionalidad y convencionalidad, el cual, empero, dejó fuera ciertas circunstancias que hubiera sido importante considerar en este caso, como el hecho de que haber negado la participación de Abigail Vasconcelos en la asamblea comunitaria tuvo que ver con su carácter de avecindada y no de mujer, porque las mujeres sí participan en las asambleas, aunque en forma muy reducida en términos numéricos. Ahora bien, de acuerdo con la directora de sNi de Oaxaca, la situación de San Bartolo es muy particular, porque ha llegado a asentarse una diversidad de personas de fuera del municipio, lo cual está impactando en una tradición en donde sólo los pobladores originarios toman decisiones sobre el nombramiento de sus autoridades.

Por otro lado, en la documentación que acompaña este expediente no se da cuenta de la existencia de un acuerdo comunitario que consistió en proponer la ampliación de dos regidurías que estarían encabezadas por mujeres, lo cual muestra dos elementos muy importantes: por una parte, la voluntad comunitaria de modificar su propia estructura interna para dar cabida a la participación política de las mujeres, lo que manifiesta a su vez una capacidad y voluntad de cambio ante las nuevas circunstancias; y, por otra parte, expresa el interés de las autoridades comunitarias acerca de que la Sala Superior no solicite al Congreso del Estado de Oaxaca la desaparición de poderes y el correspondiente nombramiento de un administrador municipal, en tanto se realice una nueva elección.

\footnotetext{
5 SUP-REC 16/2014 juicio promovido por la ciudadana Abigail Castellanos quien demanda la protección de sus derechos político-electorales en virtud de que en la elección de representantes en el ayuntamiento de San Bartolo Coyotepec Oaxaca se excluyó a las mujeres (de la Sala Superior del TEPJF).
} 
No quisiera dar la falsa interpretación de que los conflictos electorales vividos en los pueblos indígenas son causados por la autoridad electoral, pues en ocasiones la intervención de autoridades externas a los municipios indígenas inciden positivamente para hacer prevaler los intereses o decisiones de la mayoría de la población y garantizan el cumplimiento de los derechos reconocidos a los pueblos indígenas en la legislación; sin embargo, en estos dos conflictos electorales sí han potenciado las tensiones existentes o generado otras, por lo que deberemos seguir de cerca sus implicaciones para evaluar su impacto a mediano y largo plazo.

\section{Reflexiones finales}

Oaxaca fue de las primeras entidades de la república que reconoció los derechos de los pueblos indígenas; sobresalen las modificaciones realizadas en 1995 al Código de Instituciones Políticas y Procedimientos Electorales del Estado de Oaxaca (CIPPEO), y luego en el nivel constitucional, en donde se reconoció el derecho de los pueblos indígenas a elegir a sus representantes por la vía de sus sistemas normativos internos (1997). Fue también el primer estado que reglamentó su ley indígena, con lo cual se constituyó en un referente obligado para el resto del país. Pero es también una entidad con una larga historia de conflictos electorales, que tienen su origen en diversas situaciones, como las luchas indígenas por controlar el espacio municipal, por la democratización de los ayuntamientos, contra los caciques o por el acceso de las mujeres a cargos de decisión y representación. No hay duda de que otra de las fuentes de disenso político obedece a los faccionalismos internos, a veces provocados por las disputas generadas en las dos últimas décadas por la llegada de distintos partidos políticos al escenario estatal. Por estos motivos se presentan reiterados conflictos tanto en aquellos municipios que se rigen por sus sistemas normativos internos, como en aquellos que eligen a sus autoridades por la vía de los partidos políticos. Se trata de una entidad de grandes contrastes económicos, sociales y políticos, lo cual nos obliga a realizar investigaciones profundas y cuidadosas para no hacer generalizaciones que impidan dar cuenta de su diversidad y sus particularidades.

Las sentencias revisadas nos llevan a considerar que es importante que exista una voluntad de interpretación no ortodoxa en los casos de control de constitucionalidad y convencionalidad, para evitar que después de largos procesos se desconozcan los acuerdos comunitarios, pues esto podría tener resultados no deseados con implicaciones a largo plazo, como en el caso de la resolución SUP-REC 16/2014 relativa al juicio promovido por la ciudadana Abigail Castellanos, que generó varias tensiones posteriores y se tradujo en que algunos ciudadanos no se enteraron de que se habían desconocido los acuerdos de sus asambleas comunitarias, y decidieron que ya no participarían en las siguientes asambleas. En este caso, seguramente el proceso seguido llevará a que las mujeres sean tomadas en consideración en las asambleas, lo cual, sin duda, es muy importante y un acto de justicia a las demandas de las indígenas en la entidad, pero también pudiera generar una fractura de difícil recuperación en el sistema tradicional de elección de autoridades.

Una tensión que expresan los dos casos es la relativa a situar cuál es el bien jurídico a proteger: ¿las personas o el pueblo indígena? Considero que el sujeto jurídico es el pueblo indígena y que a través de estrategias como la mediación o los peritajes culturales o solicitar la opinión del amicus curiae (amigo de la corte) podrían resolverse problemáticas que tengan que ver con el respeto o inclusión de las minorías en los pueblos indígenas; tal sería el caso de las mujeres o los jóvenes.

Una de las paradojas del reconocimiento de derechos indígenas es que se ha traducido en una mayor intervención de las autoridades externas a la comunidad en sus decisiones, lo cual vulnera la autonomía de los pueblos. Pero, por otro lado, la creciente judicialización de los conflictos electorales evidencia la voluntad de resolver de forma pacífica sus desacuerdos.

En efecto, el tema de los derechos de las mujeres indígenas en muchas comunidades indígenas aún está poco atendido, sin embargo, en la mayoría de las experiencias en el nivel nacional en donde las mujeres han luchado por su inclusión política, la disputa se da en el marco de sus propias estructuras, exigiendo su inclusión o pidiendo que algunas tradiciones cambien, pero son procesos internos de negociación y conquistas. Por ello, es importante no juzgar a los pueblos con los parámetros externos o dicotómicos -dentro y fuera, tradicional-occidental-, según los cuales lo tradicional es equiparado con violatorio de derechos, y lo occidental, con garante de derechos, porque no existen tales distinciones en la realidad.

Como pudimos constatar, las resoluciones de las autoridades electorales en los niveles estatal y regional se realizaron teniendo en cuenta las tradiciones indígenas para nombrar autoridades, tal vez por un mayor conocimiento de las lógicas locales, mientras que en el federal se procedió apelando a los convenios en materia de derechos de género y bajo el principio de 
la universalidad del voto. Sería importante considerar que son las propias mujeres indígenas organizadas las que luchan por sus derechos y han señalado en múltiples ocasiones que éstos sólo podrán ejercerse cuando se respete la autonomía de sus pueblos. Se trata de escenarios complejos en donde a veces convergen intereses de caciques, partidos políticos, organizaciones y personas, y en algunos casos, acudir a instancias judiciales estatales y nacionales pone freno a inequidades, pero no puede hacerse tabula rasa, el acercamiento y conocimiento de las particularidades de cada caso permitiría una real armonización y respeto de los derechos colectivos y la legislación nacional.

Finalmente, no quisiera dejar de mencionar que en algunas ocasiones se exige a los pueblos indígenas ejercer modelos autonómicos investidos de una equidad y probidad que el sistema democrático representativo vigente no logra garantizar para nuestra nación en su conjunto, en donde el principio señala que las minorías deben respetar los acuerdos de las mayorías, pero pareciera que a los pueblos indígenas se les exige lo contrario, o sea, que la mayoría debe respetar el disenso de una, dos o cinco personas, aunque esto vulnere el acuerdo de la mayoría. Más grave es que en nuestras torcidas democracias la lógica es inversa: una pequeña minoría impone sus intereses a las grandes mayorías que claman por justicia, igualdad de trato y equidad de género. Esto no es sólo paradójico, sino lamentable, entonces, ¿por qué obligar a los pueblos indígenas a que una minoría imponga sus intereses sobre los consensos mayoritarios?

\section{Fuentes}

ANPMI

2016 "Segundo Congreso Nacional. Declaratoria", Asamblea Nacional Política de Mujeres Indígenas, 5 de septiembre, Oaxaca <https:// naaxwiinsite.files.wordpress.com/2016/09/ Aragón, OrLANDO declaratoria.pdf> [ 19 de marzo de 2018]

2013 "El derecho en insurrección. El uso contrahegemónico del derecho en el movimiento purépecha de Cherán", en Estudios e pesquisas sobres as Américas, vol. 7, núm. 2, pp. 37-69.

Bailón Corres, Moisés Jaime,

Carlos Sorroza Polo y Todd A. Eisenstadt

2016 Democracia, derechos humanos y derechos indígenas en municipios de usos y costumbres: resultados de una encuesta. Instituto Estatal Electoral y de Participación Ciudadana de Oaxaca/Comisión Nacional de los Derechos Humanos / Instituto de Investigaciones en $\mathrm{Hu}$ manidades de la Universidad Autónoma Benito Juárez de Oaxaca/American University, Oaxaca.
Bonfil, Paloma, Dalia Barrera

e IrMa Aguirre

2008 Los espacios conquistados: participación politica y liderazgo de las mujeres indígenas de México, Programa de las Naciones Unidas para el Desarrollo, México.

CONAMI

2012 Agenda política. Mujeres indígenas en México, Programa de las Naciones Unidas para el Desarrollo / Coordinadora Nacional de Mujeres Indígenas, México.

Dalton, Margarita

2012 Democracia e igualdad en conflicto: las presidentas municipales en Oaxaca, Tribunal Electoral del Poder Judicial de la Federación / Centro de Investigaciones y Estudios Superiores en Antropología Social, México.

IEPC-EG

2015 Consulta a los ciudadanos del Municipio de Ayutla de los Libres, Guerrero, para conocer si desean elegir a sus autoridades por el sistema de Usos y Costumbres o continuar con el sistema de Partidos Políticos, Comisión Especial de Participación Ciudadana, Usos y Costumbres, Voto en el Extranjero y del Diputado Migrante del Instituto Electoral y de Participación Ciudadana del Estado de Guerrero <http: / www. iepcgro.mx/PDFs / PCiudadana/Resultados Consulta.pdf> [ 19 de diciembre de 2015].

IEEPCO

2016 Más de mil mujeres ocupan cargos regidos por Sistemas Normativos, Instituto Estatal Electora y de Participación Ciudadana de Oaxaca, Oaxaca <http: / / www.ieepco.org.mx/comunicados / mas-de-mil-mujeres-ocupan-cargos-enmunicipios-regidos-por-sistemas-normativosieepco> [ 19 de junio de 2018].

JimÉnEZ BARTLETT, LELIA

y Marisol Aguilar Contreras

2013 Estándares internacionales de derechos de los pueblos indígenas aplicados a la materia electoral, Tribunal Electoral del Poder Judicial de la Federación (serie Comentarios a las Sentencias del Tribunal Electoral, 53), México.

\section{Martínez Cruz, Alicia}

2016 "Tejiendo identidades estratégicas: Asamblea de Mujeres Indígenas de Oaxaca”, en Nómadas, núm. 45, octubre, pp. 169-187 <http: / / www. redalyc.org/articulo.oa?id=105149483012> [ $1^{\circ}$ de octubre de 2017].

Méndez Lara, Marcos

2015 "Histórico Triunfo de los usos y costumbres", en El Sur. Periódico de Guerrero, 19 de diciembre <http://suracapulco.mx/9/historicotriunfo-de-los-usos-y-costumbres/> [ 19 de diciembre de 2015].

OBSERVATORIO Electoral

DE GÉNERO-IEEPCO

2016 Guía de actuación para funcionarios y funcionarias electorales en materia de género en elecciones por sistemas normativos internos, Instituto Estatal Electoral y de Participación Ciudadana de Oaxaca, Oaxaca.

\section{RECONDO, DAVID}

2007 La política del gatopardo: multiculturalismo y democracia en Oaxaca, Centro de Estudios Mexicanos y Centroamericanos/Centro de Investigaciones y Estudios Superiores en Antropología Social, México. 
RECONDO, DAVID

2014 "Etos comunitarioy derechos político-electorales del ciudadano en elecciones municipales por usos y costumbres. Evoluciones de la jurisprudencia electoral federal" <http: / / portales. te.gob.mx/vii_observatorio/sites/default / files/Etos comunitario y derechos P-E..pdf> [ 10 de octubre de 2018].

Santos López, Ana Mireya

2015 Informe Final 2011-2015. Tribunal Estatal Electoral del Poder Judicial de Oaxaca, México <http: / / teoax.org/files/Informefinal.pdf> [ 15 de marzo de 2018].

TEEPJO

2013 Informe de actividades 2013, Tribunal Estatal Electoral del Poder Judicial de Oaxaca, Oaxaca.

VAlladares de la Cruz, Laura R.

2008 "Los derechos humanos de las mujeres indígenas. De la aldea local a los foros internacionales", en Alteridades, año 18, núm. 35, pp. 47-65.

VAlladares de la CRuz, Laura R.

2014 "Sufragistas del nuevo milenio: La lucha de las mujeres indígenas por espacios de representación política”, en Héctor Tejera, Pablo Castro y Emmanuel Rodríguez (coords.), Continuida- des, rupturas y regresiones. Contradicciones $y$ paradojas de la democracia mexicana, Universidad Autónoma Metropolitana/Consejo Nacional de Ciencia y Tecnología/Juan Pablos Editor, México, pp. 379-411.

VÁzguez García, Verónica

2011 "Los derechos políticos de las mujeres en el sistema de usos y costumbres de Oaxaca", en Cuicuilco, vol. 18, núm. 50, enero-abril, pp. 185-206.

Velásguez, María Cristina

2006 "Eslabones entre el migrante y su pueblo: las mujeres en la nueva institucionalidad comunitaria indígena de la mixteca oaxaqueña”, en Blanca Suárez y Emma Zapata Martelo (coords.), Remesas. Milagros y mucho más realizan las mujeres indígenas y campesinas, vol. I, Programa de Estudios Macroeconómicos y Sociales Aplicados / Grupo Interdisciplinario sobre Mujer, Trabajo y Pobreza, México, pp. 259-300.

Velásguez, María Cristina

2011 Conflictividad electoral en municipios y comunidades que se rigen por Sistemas Normativos Internos para renovar ayuntamientos y cabildos comunitarios, Programa de las Naciones Unidas para el Desarrollo. 